\title{
Genetik Algoritma Yöntemiyle Dairesel Cepli Hidrostatik Kaymalı Yatakların Optimizasyonu
}

\author{
Fazıl CANBULUT'1 , Hakan Burçin ERDOĞUŞ2* \\ ${ }^{1}$ Makine Mühendisliği, Mühendislik Fakültesi, Erciyes Üniversitesi, Kayseri, Türkiye \\ ${ }^{2}$ Makine Programı, Makine ve Metal Teknolojileri Bölümü, İzmir Kavram Meslek Yüksekokulu, İzmir, Türkiye \\ ${ }^{1}$ canbulut@erciyes.edu.tr, *2hakan.erdogus@kavram.edu.tr
}

\begin{abstract}
Öz: Endüstride eksenel pistonlu motor ve pompalarda kullanılan kayıcı pabuçlar, çalışma esnasında hidrostatik eksenel kaymalı yatak davranışı göstermektedir. Literatürde, bu pompa ve motorların toplam güç ihtiyacını minimum ve sistemin rijitliğini maksimum olmasını amaçlayan çalışmalar bulunmaktadır. Bu çalışmada, hidrostatik eksenel kaymalı yatak için teorik analiz ve deneysel bulgulardan optimum tasarım parametreleri ve çalışma şartları belirlenmiştir. Deneysel çalışma koşulları, teorik sınırlamalarla birlikte ele alınarak çoklu kriter analizi gerçekleştirmek amacıyla yapay zeka optimizasyon yöntemlerinden biri olan genetik algoritma tekniği kullanılmıştır. Genetik algoritma optimizasyonu, çalışma şartlarını ve tasarım parametrelerini belirlemede geniş bir çözüm kümesi sunmaktadır. Yapılan çalışmalar neticesinde yatak yükleme basıncı 30 bar için yatak yarıçap oranı 0,3537 ve 0,7346 arasında, kılcal boru (orifis) çapı ( $\mathrm{mm}$ ) 0,25 ve 0,4; devir sayısı (dev/dak) 1141 ve 1496 arasında optimum parametre değerleri olarak belirlenmiştir.
\end{abstract}

Anahtar kelimeler: Hidrostatik kaymalı yataklar, eksenel pistonlu pompa, genetik algoritma optimizasyonu.

\section{Optimization of Circular Pocket Hydrostatic Sliding Bearings by Genetic Algorithm}

\begin{abstract}
The sliding pads used in industry with axial piston motors and pumps show hydrostatic axial sliding bearing behavior during operation. There are studies in the literature which aim to maximize the rigidity of the system and minimize the total power requirement of these pumps and motors. In this study, optimum design parameters and working conditions were determined from theoretical analysis and experimental findings for hydrostatic axial sliding bearing. In order to perform multiple criterion analysis, genetic algorithm technique which is one of the artificial intelligence optimization methods has been used by considering experimental working conditions with theoretical limitations. Genetic algorithm optimization offers a wide range of solutions for determining working conditions and design parameters. As a result of the studies, the pump pressure for 30 bar bearing radius ratio between 0.3537 and 0.7346 , capillary tube (orifice) diameter $(\mathrm{mm}) 0.25$ and 0.4 , speed of bearings (rpm) between 1141 and 1496 is determined as the optimum parameter value.
\end{abstract}

Key words: Hydrostatic sliding bearings, axial piston pumps, genetic algorithm optimization.

\section{Giriş}

İki katı yüzey arasındaki izafi harekete bağlı, dış sistemden basınçlı yağlayıcı akışkan gönderilerek, yağ film tabakası oluşturulması prensibine göre çalışan elemanlara hidrostatik yatak denir. İş makinelerinde eksenel pistonlu pompa ve motorlar, pozitif basınç sağlamak için yaygın bir kullanıma sahiptir. Bu pompaların en önemli kısımlarından biri kayıcı pabuç-plaka çiftidir. Kayıcı pabuçlar hidrostatik yatak prensibine göre çalışmaktadır ve geometrik özellikleri pompa ve motor performansını önemli derecede etkilemektedir. Bu çalışmada, dairesel kesitli hidrostatik yatak performansı araştırılmıştır. Yatak performansına etki eden parametrelerin uygun değerlerinin belirlenmesi için, deneysel çalışmaların gerçeğe daha yakın sonuçlar vermesinden dolayı, triboloji laboratuvarındaki test düzeneğinden faydalanılmıştır. Geometrik büyüklükler olarak kayıcı pabuç cebine basınçlı yağın gönderildiği kılcal boru/orifis çapı ile iç ve dış cep çap büyüklükleri etkili olmaktadır. Bunun yanı sıra yükleme basıncı, izafi hız ve yağlayıcı akışkan viskozitesi, hidrostatik yatak rijitliği ve yatak kayıpları, viskoz sürtünme ve sızıntı güç kaybı da önemli çalışma faktörleri arasında yerini almaktadır. Kaymalı yatakların performansının deneysel olarak ölçülmesi için test düzeneğinin kurulması ile birlikte, bir dizi çalışmalar yapılarak yatak sistemi üzerinde etkili olan parametrelerin uygun değerlerin belirlenmesine katkı sağlanmıştır [1,2]. Dairesel cepli hidrostatik kaymalı yataklarda yüzey pürüzlülüğü ve yağlama arasındaki etkileri incelemek üzere yapılan deneysel bir çalışmada, farklı yüzey pürüzlülük değerleri ( $\mathrm{Ra}$ ), orifis çapları, hidrostatik cep büyüklüklerine sahip kayıcı pabuçlar yükleme basıncı ve farklı hızlardaki etkileri araştırılmıştır $[3,4]$.

* Sorumlu yazar: hakan.erdogus@kavram.edu.tr. Yazarların ORCID Numarası: ${ }^{1} 0000-0002-0493-0550,{ }^{20000-0002-2947-7510}$ 
Hidrostatik kaymalı yataklarda ihtiyaç olan toplam gücün en az ve sistemin taşıması gereken yükün en fazla olması yapılan teorik ve deneysel çalışmaların temelini oluşturmuştur. Bu kapsamda araştırmalar, hidrostatik yatak sisteminin çalışma şartlarına etki eden bazı parametreler üzerine yoğunlaşmıştır. Bunlar; yatak cebinde oluşan basınca doğrudan etki eden kılcal boru (orifis) çapı, hidrostatik yatak alanını belirleyen yatak yarıçap oranı ve sisteme sevk edilen akışkan yağ debisi ve sürtünmeye harcanan güce etki eden devir sayısıdır.

Belirli sınırlamalar olması durumunda, bilinmeyen parametre değerlerinin bulunması veya sezgisel algoritmalar gibi herhangi bir amacı gerçekleştirmek için yakınsama özelliğini kullanarak kesin çözüme yakın bir değer en iyileme veya optimizasyon olarak adlandırılmaktadır. Dairesel cepli hidrostatik kaymalı yataklarda ihtiyaç olan toplam güç için yapılan bir optimizasyon çalışmasında, yatak katsayısı tanımlanmış ve minimum sıcaklık artışı ile birlikte minimum toplam güç ihtiyacı incelenmiştir. Buna göre, ikili kriterle yapılan optimizasyonun, yatakta meydana gelen sıcaklık değişimi ve gerekli olan toplam güç miktarı açısından tek kriterli optimizasyona göre daha iyi sonuç verdiği görülmüştür [5]. Benzer şekilde parçacık sürüsü optimizasyon yöntemini kullanarak yapılan benzer bir başka çalışmada, çeşitli tasarım değişkenleri ve çalışma parametreleri belirlenmiştir. Mühendislik optimizasyonunda yapay zekâ algoritmaları çoklu analiz açısından daha uygun sonuçların elde edilmesini sağlamıştır [6]. Radyal kaymalı yatağın optimum tasarımını amaçlayan bir başka çalışmada, genetik algoritma yaklaşımlı optimizasyon yapılmıştır. Genetik algoritma yaklaşımıyla yapılan optimum tasarımın geleneksel optimizasyon yöntemleriyle kıyaslandığında, daha esnek ve etkin olduğu sonucuna varılmıştır [7-9]. Isı eşanjörlerinde bulunan kanatların genetik algoritma yöntemiyle optimizasyonu üzerine yapılan bir çalışmada elde elden büyüklüklerle, önceden üretilen model karşılaştırıldığında 1sı transfer oranında artışa ve güç tüketiminde azalma gözlenmiștir [10].

Eksenel pistonlu pompalarda bulunan ve dairesel cepli eksenel kaymalı yatak özelliği gösteren kayıcı pabuçlar için deneysel ve teorik analiz sonrasında tasarım parametreleri ve en uygun çalışma şartları belirlenmiştir. Genetik algoritma optimizasyon yöntemiyle, maksimum sistem rijitliği ve minimum toplam güç ihtiyacı için gerekli olan değerler çözüm kümesi kapsamında tespit edilmiştir ve elde edilen veriler karşılaştırılarak sınır değer aralıkları oluşturulmuştur.

\section{Teorik Analiz}

Hidrolik güç iletim sistemleri elemanlarından biri olan kayıcı pabuçlar veya kaymalı yatakların verimliliği önemli çalışma konularından biri olmuştur. Şekil 1'de kesit görünüşü verilen bir eksenel pistonlu pompada, rotorun açısal hareketiyle kaymalı yatak üzerinde bulunan pistonların ileri ve geri hareketleri sayesinde pompa basıncı oluşmaktadır. $\mathrm{Bu}$ durum, sabit duran eğim plakası ile kaymalı yatak arasında oluşan kayma hareketiyle gerçekleşmektedir [11]. Şekil 1'de pirinç malzemeden imal edilen ve deneysel analiz için kullanılan bir hidrostatik eksenel kaymalı yatak kesiti görülmektedir.

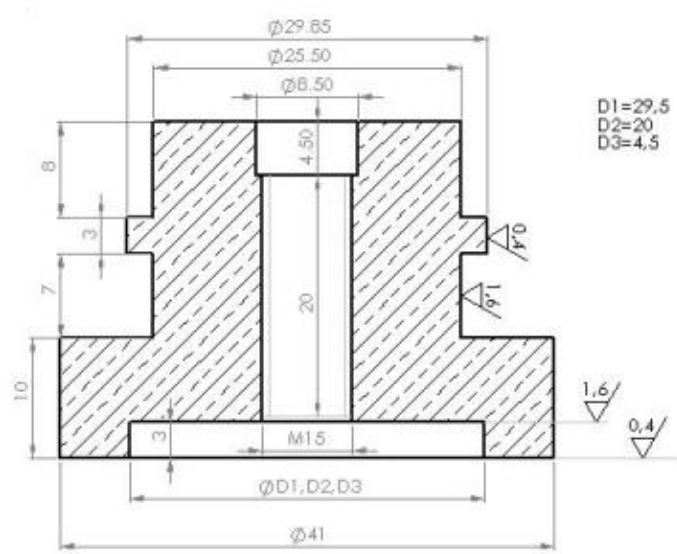

Şekil 1. Hidrostatik eksenel cepli kaymalı yatak. 


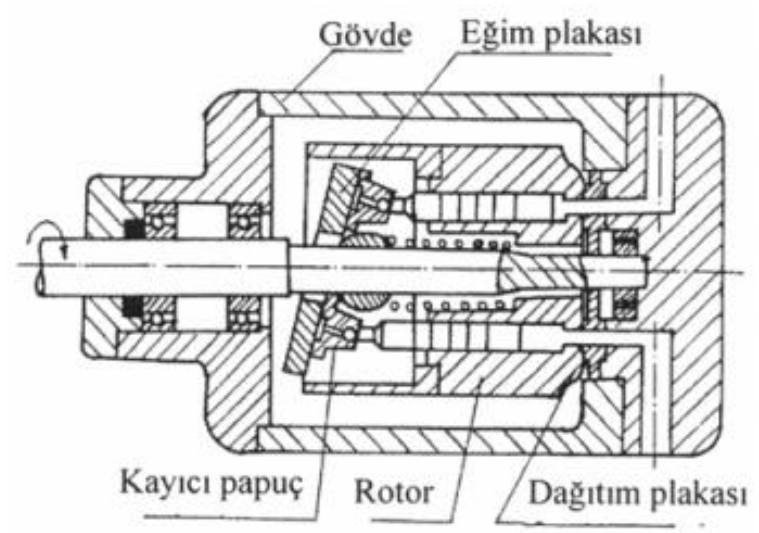

Şekil 2. Eksenel pistonlu pompa ve elemanları.

Hidrodinamik yağlama sisteminin incelenmesi Navier - Stokes hareket denklemine dayanır. Bu denklemle birlikte çözümü süreklilik denkleminde ele alınır. Dairesel cepli bir hidrostatik yağlama sisteminde oluşan sıv1 sürtünmesi için sınır şartlarına göre sabitler tespit edilirse, basınç fonksiyonundan radyal doğrultudaki akış debisi Eş. 1 denkleminden hesaplanabilir.

$Q_{d}=\frac{\pi \mathrm{p}_{\mathrm{c}}}{6 \mu} \frac{\mathrm{h}^{3}}{\operatorname{Ln}\left(\mathrm{r}_{\mathrm{d}} / \mathrm{r}_{\mathrm{i}}\right)}$

$\mathrm{Bu}$ denklemde $\mathrm{r}_{\mathrm{d}} / \mathrm{r}_{\mathrm{i}}$ yatak yarıçap oranını göstermektedir. Şekil 1'de deneysel analiz için kullanılan hidrostatik kaymalı yatak cebine karşılık gelen $p_{c}$ basıncının, $p_{p}$ piston basıncına oran $1 p_{c} / p_{p}$, bu sistemlerin çalışma faktörlerinde belirleyici rol oynamaktadır. Kılcal boru veya orifis içerisinden geçen akışkan debisi cep basıncı ve pompa basıncına bağlı olarak değişmektedir. Bu denklem Eş.2’de verilmektedir.

$\mathrm{Q}_{\mathrm{k}}=\frac{\pi \mathrm{d}^{4}}{128 \mathrm{l} \mu}\left(\mathrm{p}_{\mathrm{p}}-\mathrm{p}_{\mathrm{c}}\right)$

Bu eşitlikte; $Q_{k}$ kılcal borudan geçen akışkan debisi, 1 kılcal boru uzunluğu ve $\mu$ akışkanın viskozitesi olarak tanımlanmaktadır. Sabit yükleme basıncında, cep içindeki $\mathrm{p}_{\mathrm{c}}$ 'nin yükselmesi, kısıcı eleman olan kılcal borudan geçen debinin azalmasına ve aksi hali ise büyümesine sebebiyet vermektedir. Hidrostatik yataklama sisteminin önemli bileşenlerinden olan pompa ve cep basıncı, toplam gücün belirlenmesinde kullanılmaktadır. Buna göre, eksenel hidrostatik kaymalı yataklarda gerekli olan toplam güç, pompa gücü ve sürtünme gücünün toplamı olarak ifade edilmektedir. Yatak için gerekli olan toplam güç ihtiyacı Eş.3'deki gibi verilmektedir [13].

$$
\begin{aligned}
& P_{\text {toplam }}=\mathrm{P}_{\text {sürtünme }}+\mathrm{P}_{\text {pompa }} \\
& \mathrm{P}_{\text {toplam }}=\mathrm{K}_{\mathrm{s}} \mu \frac{\omega^{2} \mathrm{r}_{\mathrm{d}}{ }^{2}}{\mathrm{~h}} \mathrm{~A}+\frac{1}{\eta_{\mathrm{p}}} \mathrm{K}_{\mathrm{p}}\left(\frac{\mathrm{F}}{\mathrm{A}}\right)^{2} \frac{\mathrm{h}^{3}}{\mu}
\end{aligned}
$$

Eş.4'te verilen $K_{p}$ pompa gücü ve $K_{s}$ sürtünme gücü için geometrik katsayılardır. Bunlarla birlikte, hidrostatik sistemdeki debi hesabı için $\mathrm{K}_{\mathrm{q}}$, yük taşıma kapasitesi için ise $\mathrm{K}_{\mathrm{f}}$ kuvvet katsayısı kullanılmaktadır. $\mathrm{Bu}$ katsayılar, yatak yarıçap oranına bağlı olarak değişmektedir. Boyutsuz geometrik katsayıların yatağın iç ve dış yarıçapına bağlı olarak değişimi Şekil 3'de verilmiştir. Eş.4'e göre toplam gücün minimum yapılmasını sağlayan pompa gücü katsayısını minimum yapan değer 2,5713 olarak elde edilmiştir. Bu şartlarda yarıçap oranı 0,5335 olduğunda pompa gücü minimum olmaktadır. Solmaz [5], yapmış olduğu çalışmada elde etmiş olduğu bu değerin teorik olarak sürtünme gücü katsayısına göre pompa gücü katsayısının daha fazla etkisi olduğu sonucuna ulaşmıştır. 


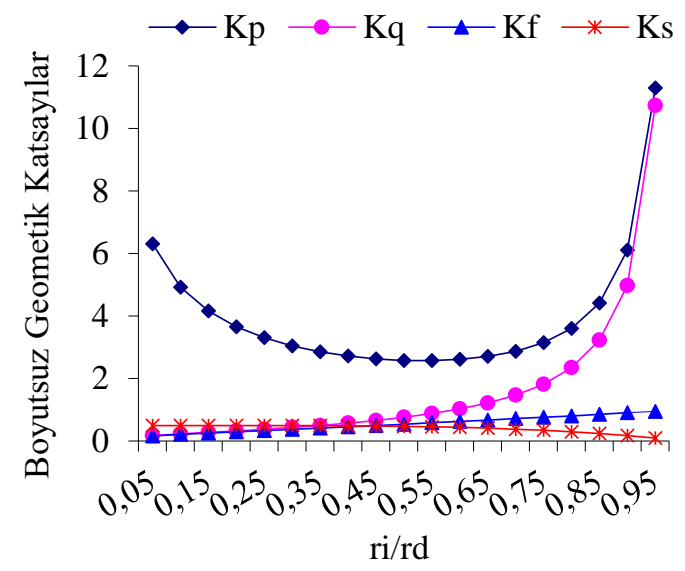

Şekil 3. Boyutsuz katsayıların yatak yarıçap oranına göre değişimi.

Dairesel cepli kaymalı yatak tasarımda önemli bir fonksiyon olarak ele alınan hidrostatik sistem rijitliği, Eş.5’te verildiği gibi film kalınlığına göre sistemin taşıdığı yük değişimi olarak tarif edilmektedir [13].

$\mathrm{k}=-\frac{\mathrm{dF}}{\mathrm{dh}}$

$\mathrm{k}=3 \mathrm{~K}_{\mathrm{f}} \mathrm{Ap}_{\mathrm{c}} \frac{1}{\mathrm{~h}}$

Yarıçap oranının kayma yüzeyindeki yük dengesi Eş.6 denkleminde görüldüğü gibi cep basıncına ve yarıçap oranına bağlı olarak değişmektedir. Hidrostatik sistem rijitliği hesaplaması için yatak dış yarıçapı $20,5 \mathrm{~mm}$, kılcal boru veya orifis boyu $5 \mathrm{~mm}$ ve çap $0,5 \mathrm{~mm}$ geometrik özelliklerine sahip olan dairesel cepli yatağa $30 \mathrm{~Pa}$ pompa basıncı uygulanmasıyla gerçekleştirilmiştir.

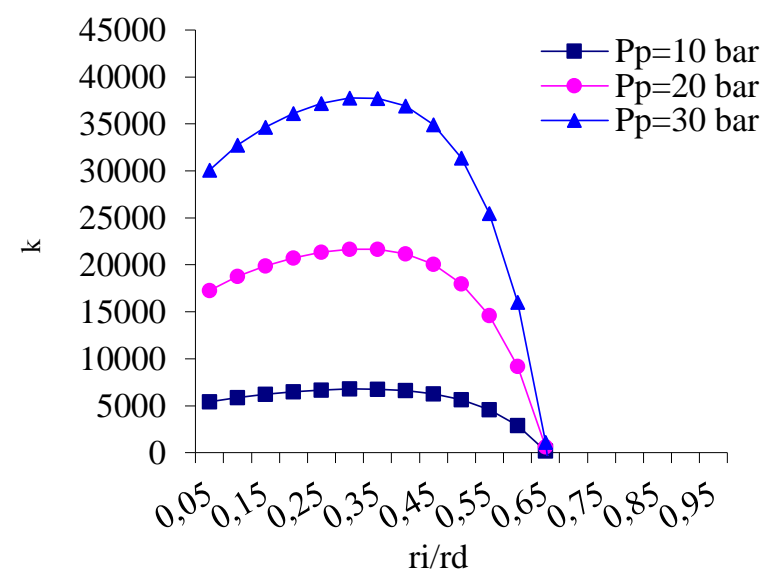

Şekil 4. Yatak yarıçap oranına bağlı olarak hidrostatik sistem rijitliğindeki değişim [5,12].

Şekil 4'den görüldüğü gibi yarıçap oranına bağlı olarak yağ film kalınlığında meydana gelen değişim sürtünme güç kaybını dolayısıyla toplam gücü ve hidrostatik sistem rijitliği değerlerini etkilemektedir. $\mathrm{Bu}$ değerlerin, çalışma faktörleri açısından optimum nitelikte bir tasarım parametresi olarak yarıçap oranının önemi açısından gerekli olduğu anlaşılmaktadır. Yatak rijitliğinin yarıçap oranlarına göre değişimi incelendiğinde, maksimum olduğu yarıçap oranı değerinin $r_{i} / r_{d} \leq 0,3537$ olduğu tespit edilmiştir. Bu değer, teorik analiz açısından hidrostatik sistem rijitliğini optimum yapan çalışma parametresi olarak kabul edilmiştir. Genetik algoritma optimizasyonu yapılırken, minimum toplam güç ihtiyacı fonksiyonuna sistemin yük taşıma kapasitesi bakımından tasarım sınırlaması olarak dâhil edilmiştir. 


\section{Deneysel Yöntem}

Hidrostatik eksenel kaymalı yatakların çalışma parametrelerinin belirlenmesi kapsamında kurulan deney tesisatı Şekil 5'te görülmektedir. Ana deney sisteminin alt sistem elemanları veri toplayıcısı, test ünitesi, ölçekli kap, hidrolik pompa, kontrol valfi ve servo motordan oluşmaktadır. Ana test ünitesinde ölçüm yapmak için termokupl ve manometre kullanılmışıtır. Eksenel pistonlu pompalardaki eğim plakası görevinde olan döner plaka, servo motor yardımıyla tahrik edilmektedir. Güç ünitesi bölümünde servo motorun hassasiyeti kontrol edilmektedir [1].
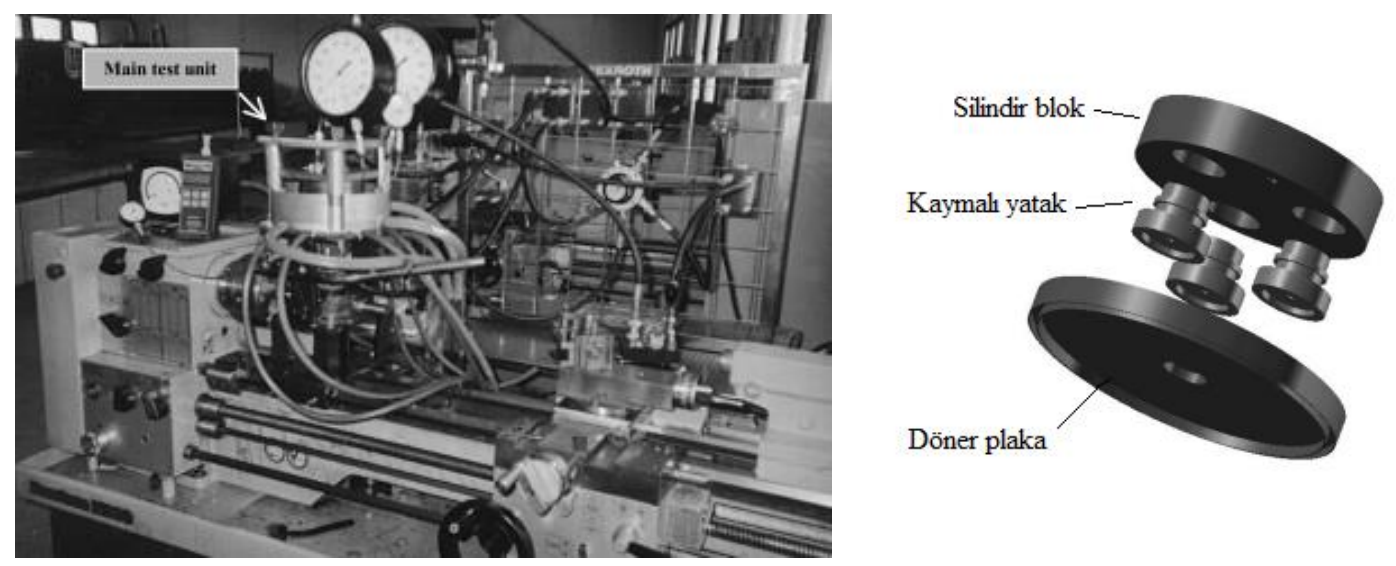

Şekil 5. Eksenel hidrostatik-hidrodinamik deney seti ve kaymalı yatakların yerleşimi [4].

Silindir bloğa yerleştirilen kaymalı yatakların z-yönünde hareketi serbest bırakılmıştır. Döner plaka ve silindir blok arasındaki mesafe z-yönünde ayarlanabilir bir mil yardımıyla sağlanmıştır. Kontrol ünitesi bölümünde yer alan veri toplayıcısı, test ünitesinden gelen elektriksel ölçümleri tork, basınç ve sıcaklık değeri olarak kaydetmektedir. Kaymalı yatağın ön, arka ve yan kenarındaki basınç değişimi sensörlerle ölçülmüştür. Kaymalı yatak içerisine yerleştirilen kılcal boru aracılı̆̆ıyla bu bölgeler üzerinde basınç değişimi sağlanabilmektedir.

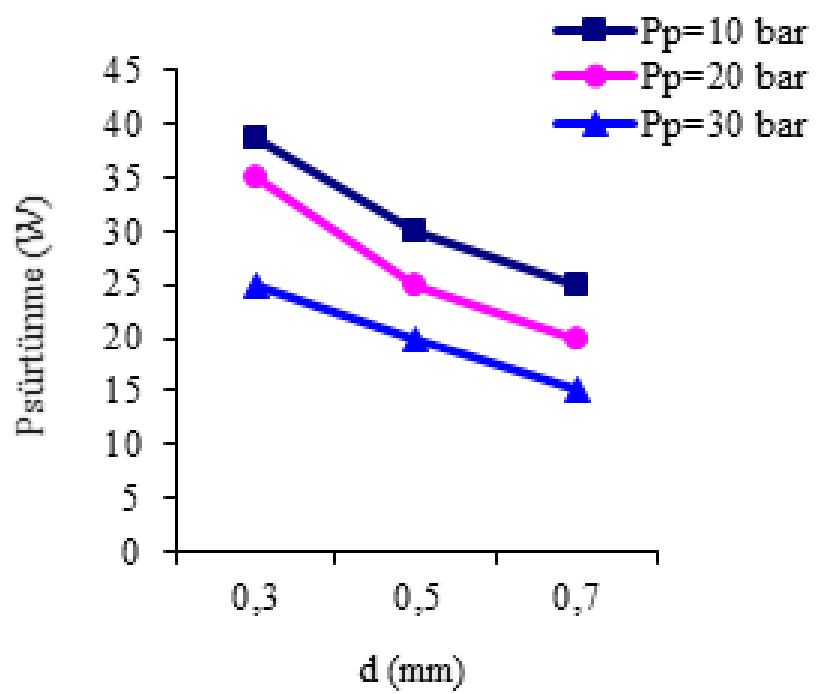

Şekil 6. Sürtünme güç kaybının kılcal boru çapına göre değişimi.

Kaymalı yatak cebine üst bölgeden yağ gönderen ve iç çapı $0,3-0,5$ ve $0,75 \mathrm{~mm}$ olan kılcal borular (veya orifisler) kullanılmıştır. Kaymalı yataklar üzerine yapılan eşit yükleme basınçları ve çalışma hızları deneysel yöntemin temelini oluşturmuştur. Ortam sıcaklığ $20^{\circ} \mathrm{C}$ civarında korunmuştur. Bu nedenle deneyde hava 
soğutmalı bir sistem kullanılmıştır. Her deneyden önce ve sonra yağ sıcakları dijital termometre ile ölçülerek kaydedilmiştir. Deneyde yükleme basınçlarının basınç denetim valfi ile ayarlanması, yataklar altından çıkan akışkan miktarının ölçülmesi için kullanılan kronometre ve ölçüm kabının yerleştirilmesi, başlangıç ayarlarından sonra sistemin tümü için hazır hale getirilmektedir.

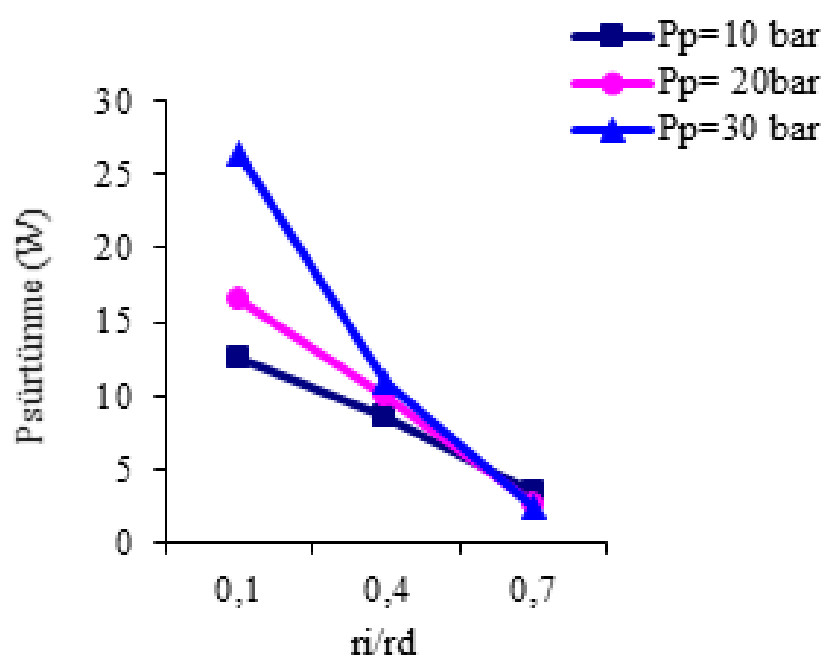

Şekil 7. Sürtünme güç kaybı ve yarıçap oranı değişimi.

Silindir bloğuna yağ gönderen basınç denetim valfi ile basınç 10, 20 ve 30 bar olmak üzere üç farklı değerde ayarlanarak, yatakların farklı yüklerde incelenmesi sağlanmaktadır. Her bir yükleme basıncı için döner tabla 250, 500, 900 ve 1500 dev/dak olarak çalıştırılmıştır. Her bir çalışma için tezgâhın yük altında çalışırken harcadığı güç miktarları bir wattmetre ve sistemden sızan yağ akışı ölçekli kap ile belirlenmiştir. Şekil 6 ve 7 'da görüldüğü gibi, kılcal boru çapı ve yarıçap oranının artmasıyla sürtünme güç kaybı azalmıştır. Aynı pompa basıncı, döner plaka ile kaymalı yatak arasında oluşan yağ film tabakasındaki artışla birlikte sürtünme gücünün azalmasına sebep olmuştur. Yağ filminin artması sisteme ulaşan debi miktarının artması anlamına gelmektedir. Pompa basıncının yükselmesi ile birlikte kılcal boru çapının genişlemiş olması debi miktarını Şekil 7'de görüldüğü gibi yükseltmiştir.

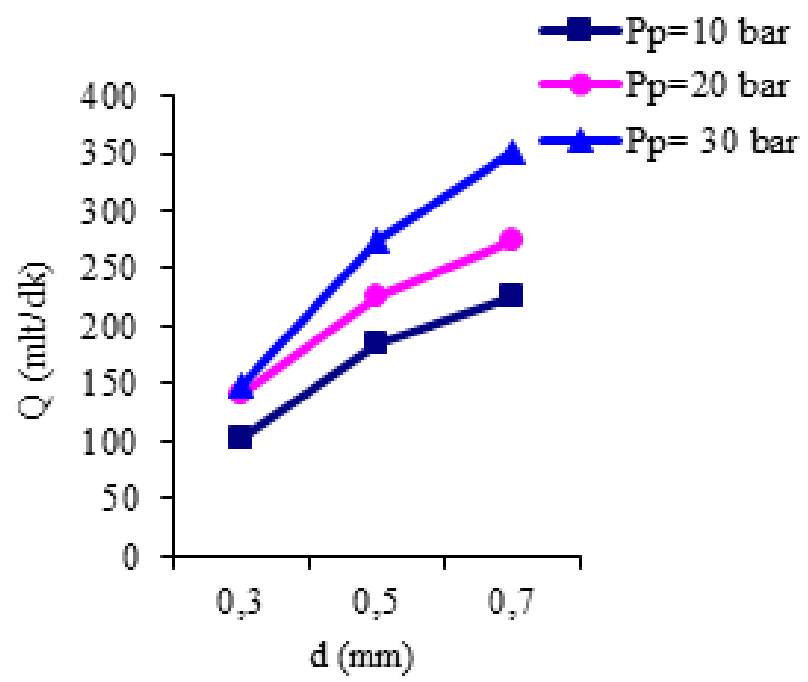

Şekil 8. Kılcal boru çapına bağlı olarak akışkan debisi değişimi. 


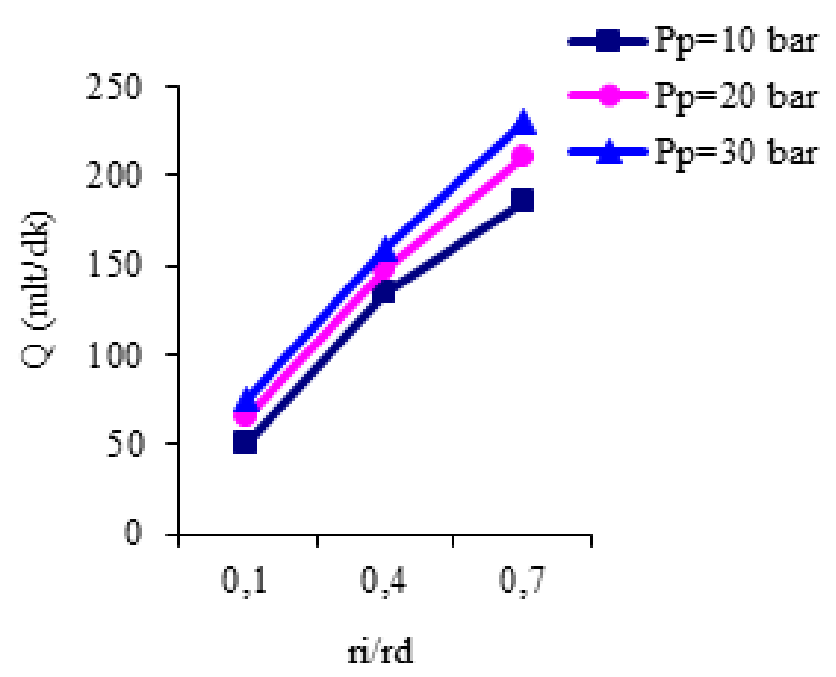

Şekil 9. Debinin yarıçap oranına bağlı olarak değişimi.

Deney sisteminde kayıcı plaka üzerinde yer alan üç kaymalı yatak için ölçülen değerler sayısal olarak üçe bölünerek bir yatak için oluşan sürtünme güç kaybı ve debi miktarı hesaplanmıştır. Ayrıca, bu deney sisteminde yağ giriş ve çıkış sıcaklıkları, piston yükleme ve hidrostatik cep ve hidrodinamik yatak basınçları da belirlenebilmektedir. Deneysel çalışma için kullanılan kaymalı yatakların dış yarıçapı 20,5 mm de sabit tutularak, pabuç iç çapları yarıçap oranı $0,1-0,4$ ve $0,7 \mathrm{~mm}$ değerlerine göre işlenmiştir. Şekil 8 ve 9 'da görüldüğü gibi kılcal boru ya da orifis çapı, devir sayısı ve hidrostatik cep oranındaki değişimler debi ve sürtünme güç kaybında etkili olmaktadır. Yarıçap oranının artmasıyla yağ film kalınlığı artacağından sürtünme güç kaybı da aynı doğrultuda artış göstermektedir. Eksenel pistonlu pompaların verimli çalışmasını sağlayan en önemli makine elemanı olarak kaymalı yataklar üzerine yapılan deneysel ve teorik analiz neticesinde, optimum çalışma şartları ve tasarım değişkeni değerlerinin; pompa basınc 30 bar, yarıçap oranı $0,55 \mathrm{~mm}$, devir sayısı 1000 dev/dak ve kılcal boru çapı ise $0,3-0,5 \mathrm{~mm}$ arası değişiklik gösterdiği belirlenmiştir [4].

\section{Genetik Algoritma Optimizasyonu}

Optimizasyon problemi, belirlenen sınırlar çerçevesinde, bilinmeyen değerlerin bulunmasını içeren bir problem olarak ifade edilmektedir. Bu işlem için öncelikle karar veya tasarım parametreleri tanımlanmalıdır. Sınırlamalar, karar parametrelerine bağlı olarak ifade edilmektedir. Bazı sınırlamalar eşitsizlik, bazıları ise eşitlik biçiminde olabilir [12]. Genetik algoritmalar doğal seçim ilkelerine dayanan bir arama ve optimizasyon yöntemidir. Bu algoritmalar fonksiyon optimizasyonu, çizelgeleme, mekanik öğrenme, tasarım ve hücresel üretim gibi alanlarda başarıyla uygulanmaktadır. Geleneksel optimizasyon yöntemlerinden farklı olarak, parametre kümesinin kodlanmış biçimleri kullanılır. Olasılık temelinde çalışan genetik algoritmalar, çözüm uzayının tamamını değil belirli bir kısmını araştırarak çözüm aramaktadır. Genetik algoritmalar, mekanizma tasarımlarında verdiği sonuçlarla mühendislik optimizasyonlarında tercih edilmektedir [14-16].

Genetik Algoritma (GA), çözüm uzayındaki bir noktayı kromozom adı verilen ikili bit dizisi ile kodlar ve bu noktanın bir uygunluk değeri hesaplanır. Popülasyon olarak tanımlanan noktalar kümesi içerdiğinden tek bir noktaya bağlı değildir. Bu popülasyonda, çaprazlama ve mutasyon gibi genetik operatörlerle yeni kuşaklar oluşturulur. En iyi uygunluk değerine ulaşıncaya kadar popülasyon kuşakları yenilenir [15].

Dairesel cepli hidrostatik yatakların konstrüksiyonunda etkili olan çalışma şartları ve tasarım değişkenleri genetik algoritma yaklaşımıla incelenmiştir. Teorik ve deneysel analizler sonucunda belirlenen ve yatak performansında etkili olan değişkenler yatak yarıçap oranı, kılcal boru (orifis) çapı ve devir sayısı değerleri;

$$
\begin{array}{lr}
\text { Yatak yarıçap oranı (mm) } & 0,05 \leq \mathrm{r}_{\mathrm{i}} / \mathrm{r}_{\mathrm{d}} \leq 0,95 \\
\text { Kılcal boru (orifis)çapı (mm) } & 0,1 \leq \mathrm{d} \leq 0,7 \\
\text { Devir sayısı (dev/dak) } & 750 \leq \mathrm{n} \leq 1500
\end{array}
$$


olarak optimizasyon işlemine alınmıştır. Deneysel çalışmalar sonucunda, kılcal boru çapı üst sınır değeri olan 0,7 mm'den sonra atalet faktörü oluştuğu ortaya çıkmıştır. Ayrıca, devir sayısı için belirlenmiş olan $750 \mathrm{dev} / \mathrm{dak}$ kaymalı yatak ile döner tabla arasındaki tam sıvı sürtünmesinin sağlanması ve deneysel olarak güç kayıplarının minimum olduğu değer olarak tespit edilmiştir [12]. Genetik algoritma optimizasyonu için minimize edilmek istenen hedef fonksiyonu hidrostatik kaymalı yatak için gerekli olan toplam güç ihtiyacı denklemi dikkate alınarak Eş.8 eşitliğindeki gibi gösterilmektedir.

$\mathrm{F}_{\mathrm{obj}}=\mathrm{MinP}_{\text {toplam }}$

$\mathrm{F}\left(\mathrm{r}_{\mathrm{i}} / \mathrm{r}_{\mathrm{d}}, \mathrm{d}, \mathrm{n}\right)=\mathrm{P}_{\text {sürtünme }}+\mathrm{P}_{\text {pompa }}$

\section{1 Çalışma şartları için sınırlamalar}

Tasarım değişkenleri kısıtlayan ve optimum tasarımın oluşmasını sağlayan kriterler, tasarım sınırlamalarıdır. Hidrostatik eksenel yataklarda minimum toplam güç ihtiyacı için belirlenen ve çalışma şartlarının etki ettiği sinırlamalar Eş. 9 ve Eş. 10'da verilmiştir.

$\mathrm{g}_{1}(\mathrm{x})=\mathrm{h}_{\min }-h<0$

$\mathrm{g}_{2}(\mathrm{x})=\mathrm{W}-\mathrm{W}_{\max }<0$

Minimum toplam gücü elde edebilmek için deneysel çalışma sonucunda belirlenen sıvı sürtünmesinin oluşmasında gerekli minimum yüzey pürüzlülük değeri $\mathrm{h}_{\min }$ ve hidrostatik sistem rijitliğinin maksimum olduğu yarıçap oranı değerindeki yük taşıma kapasitesi $\mathrm{W}_{\max }$ temsil etmektedir.

\section{2 İkili sistem planlaması}

GA geliştirilmesinde, problemin çözümü için, tasarım değişkenlerinin aynı boyutlara sahip bitler dizisi biçiminde kodlanması Tablo 1'de verilmiş̧ir. Optimizasyon gerçekleştirmede seçilmesi gereken kontrol parametreleri için literatürde yer alan çalışmalardan faydalanılmıştır. Frezeleme için optimum kesme şartlarının araştırmasına yönelik yapılan bir GA optimizasyonunda 0,75 çaprazlama oranı ve 0,01 mutasyon oranı kullanılmıştır [17].

Tablo 1. Tasarım değişkenleri için ikili sistem planlaması.

\begin{tabular}{r|ccc} 
& $r_{i} / r_{d}$ & $\mathrm{~d}$ & $\mathrm{n}$ \\
\hline Alt sınır & 0,05 & 0,1 & 750 \\
Üst sınır & 0,95 & 0,7 & 1500 \\
Hassasiyet & 0,001 & 0,001 & 5
\end{tabular}

Benzer bir çalışmada, tornalama için önceden belirlenen kesme sınırlamaları dahilinde maliyeti minimize eden optimal çalışma parametreleri belirlenirken 0,3 çaprazlama oranı ve 0,001 mutasyon oranı olarak alınmıştır [18]. GA optimizasyonu, çalışma şartları ve tasarım parametrelerini seçmede karar almak için kapsamlı bilgi vermektedir. Deneysel çalışmada kullanılan koşullar, teorik analiz ile birlikte sınırlandırıldığında aynı çalışma şartlarında toplam güç ihtiyacı farklı tasarım değişkenleri tarafından belirlenebilmektedir.

GA optimizasyon yöntemi, minimum toplam güç ihtiyacı problemi için geniş bir çözüm kümesi sunmaktadır. Dairesel cepli hidrostatik kaymalı yataklarda deneysel ve teorik çalışmalara göre optimum tasarımı sağlayabilmek için MATLAB Genetic Algorithm Tool kullanılmıştır. Bu amaçla, üç farklı pompa basıncında (10, 20 ve 30 bar) program çalıştırılmıştır. Yapılan analiz neticesinde Tablo 2'de görüldüğü gibi sınır değer aralıkları elde edilmiştir. 
Tablo 2. Üç farklı optimizasyon sonrası elde edilen sınır değer aralıkları.

\begin{tabular}{l|ccc}
\multicolumn{2}{c}{ Optimizasyon-1 } & Optimizasyon-2 & Optimizasyon-3 \\
\hline$r_{i} / r_{d}(\mathrm{~mm})$ & $0,3668-0,7207$ & $0,3537-0,7124$ & $0,3537-0,7346$ \\
$\mathrm{~d}(\mathrm{~mm})$ & $0,3-0,47$ & $0,27-0,42$ & $0,25-0,4$ \\
$\mathrm{n}(\mathrm{dev} / \mathrm{dak})$ & $1166-1497$ & $1182-1499$ & $1141-1496$ \\
\hline $\operatorname{Min} P_{\text {toplam }}(\mathrm{W})$ & 10,48 & 8,13 & 6,64
\end{tabular}

\section{Bulgular ve Tartıșma}

Eksenel pistonlu pompaların verimli çalışmasında etkili olan kayıcı pabuç (kaymalı yatak) tasarımları, hidrostatik şartlarda ele alındığında bazı parametreler ortaya çıkmaktadır. Bu çalışmada söz konusu parametreler, kaymalı yatağın çalışma şartları ve tasarım değişkenleri olarak ele alınmıştır. Deneysel bulgulardan faydalanılarak, dairesel cepli hidrostatik eksenel kaymalı yatağın verimli çalışması amacıyla ihtiyaç olan toplam güce; kılcal boru çapı, yatağın yarıçap oranı, yükleme basıncı ve devir sayısı etkili olmaktadır. Deneysel bulgularla tespit edilen bu parametrelerin, aynı çalışma şartlarında optimum olması istenen değerler için teorik analizi gerçekleştirilmiştir. Hazırlanan bilgisayar programı yardımıyla, deneysel olarak ölçülemeyen yağ film kalınlığı, ya $\breve{g}$ debisi ve pompa gücü gibi büyüklükler hesaplanmıştır. Buna göre, yarıçap oranının artmasıyla hem teorik hem de deneysel sürtünme güç kaybının azalmakta olduğu görülmüştür. Yarıçap oranının düşük değerinde $\left(r_{i} / r_{d}=0,1\right)$, teorik ve deneysel değerler arasındaki farkın büyük olması, teorik analizde yapılan kabullerden kaynaklanmaktadır. Yarıçap oranının yüksek değerinde $\left(r_{i} / r_{d}=0,7\right)$, her iki analiz sonucu birbirine yaklaşmaktadır. Döner tabla ile kaymalı yatak arasında sızan yă̆ debisi miktarı yarıçap oranının artmasıyla artmaktadır. Toplam güç ihtiyacının belirlenmesinde, yatak ile sürtünme yüzeyi arasındaki yağlamanın sağlanması için pompa gücünün önemi vurgulanmıştır. Pompa gücünün maksimum olduğu yarıçap oranı değeri 0,5335 olarak tespit edilmiştir. Ayrıca, hidrostatik sistem rijitliğinin oluşmasında ve yük taşıma kapasitesini meydana getiren unsurlara bakıldığında, optimum nitelikte olan bir yağ tabakası kalınlığı h'a, maksimum rijitliğe karşılık geldiği anlaşılmaktadır. Sistemin yük taşıma kabiliyetini belirleyen temel parametrelerden birisi olarak yağ film kalınlığı ile birlikte yarıçap oranının da belirleyici rol oynadığı anlaşılmıştır. Teorik analiz yapılırken, hazırlanan bir program yardımıyla film kalınlığının yarıçap oranı 0,3537 değerine ulaştıktan sonra azaldığı ve sistemin rijitliğgini kaybettıği görülmüștür. Benzer şekilde, deneysel bulgularda 1000 dev/dak olarak belirlenen devir sayısının optimizasyon sonuçlarında $1141 \mathrm{dev} / \mathrm{dak}$ alt sınır değerinde olduğu görülmüştür. Kılcal boru çapının artmasıyla doğru orantılı olarak yağ film kalınlığı ve debi miktarının yükseldiği deneysel bulgularla elde edilmiştir. GA optimizasyonlarında kılcal boru çapı değeri en düşük $0,25 \mathrm{~mm}$ ve en yüksek $0,47 \mathrm{~mm}$ olarak belirlenmiştir. Deneysel çalışma sonucunda $0,3-0,5$ $\mathrm{mm}$ arası optimum değerde olduğu kabulü yapıldığından, optimizasyondan alınan değer aralıklarının deneysel bulguları doğruladığı görülmektedir. Bulgulara göre minimum toplam güç ihtiyacı 6,64 W olarak belirlenmiştir.

\section{Sonuçlar}

Deneysel bulgular ve teorik analiz sonuçlarına göre toplam güç ihtiyacının minimum ve hidrostatik sistem rijitliğini maksimum yapan tasarım değişkenleri ve çalışma şartları için optimizasyon işlemi gerçekleștirilmiş̧tir. Optimizasyonu sınırlayan yağ film kalınlığı ve yük taşıma kabiliyeti, toplam güç ihtiyacı fonksiyonu minimize edilirken çözüm kümesinin oluşmasında ciddi katkı sağlamıştır.

Çoklu kriter analizi problemlerinin çözümünde genetik algoritma kullanılması, çözüm kümesini sınırlandırmakta ve sonuca yakınsama sağladığı bilinmektedir. Buna göre, üç farklı pompa basıncı giriş parametresi olarak kullanılarak elde edilen yarıçap oranı, kılcal boru çapı ve devir sayısı değerleri deneysel ve teorik bulgulara yakın sonuç vermiştir.

Eksenel pistonlu pompa veya motorların tasarımında önemli bir eleman olan kaymalı yatakların konstrüksiyonunda, yüzey pürüzlülüğü faktörünün bir matematiksel model olarak ele alınarak tasarım kısıtlaması olarak dâhil edildiğinde teorik olarak gerçeğe yakın sonuçlara ulaşılabilir. Ayrıca, yapay zeka optimizasyon algoritmalarından karınca koloni algoritması, parçacık sürüsü optimizasyonu, yapay 1sıl işlem, tabu araştırma algoritması ve yapay bağışıklık algoritması yöntemleri kullanılarak optimizasyonun mukayese alanı genişletilebilir. 


\section{Kaynaklar}

[1] Koç E, Canbulut F. Eksenel hidrostatik - hidrodinamik yatak deney düzeneği tasarımı ve imalatı. ODTÜ Ankara 1990; 561-570, 19-21 Eylül.

[2] Koç E, Canbulut, F, Canbulut F. Hidrostatik eksenel kaymalı yatakların teorik ve deneysel analizi- sistem rijitliği. Mühendis ve Makina 1991; Cilt-38 Say1:444.

[3] Koç F, Kaymalı Yataklarda Yüzey Pürüzlülüğünün Yağlamaya Etkilerinin Deneysel Analizi. Yüksek Lisans Tezi, Erciyes Üniversitesi Fen Bilimleri Enstitüsü Makine Mühendisliği ABD, Kayseri. 1996.

[4] Canbulut F. The experiment analyses of the effects of the geometric and working parametres on the circular hydrostatic thrust bearings. International Journal Series C Mechanical Systems, Machine Elements and Manufacturing 2005; 48(4), 715-722.

[5] Solmaz E, Eksenel Hidrostatik Kaymalı Yatakların Optimum Tasarımı. Doktora Tezi, Uludağ Üniversitesi Fen Bilimleri Enstitüsü, Bursa, 2000.

[6] He S, et al. An improved particle swarm optimizer for mechanical desing optimization problems, engineering optimization. Engineering Optimization 2004; 36(5), 585-605.

[7] Saruhan H, et al. Design optimization of tilting pad journal bearing using genetic algoritm. International Journal of Rotating Machinery 2004; 10(4),s: 301-307.

[8] Uysal Ü, Dairesel Cepli Hidrostatik Yataklarda Kayma Yüzeyindeki Sıcaklık Dağılımının Teorik ve Deneysel İncelenmesi. Yüksek Lisans Tezi, Erciyes Üniversitesi, Kayseri, 1993.

[9] Corbera S, Olazagoitia, JL, \& Lozano JA. Multi-objective global optimization of a butterfly valve using genetic algorithms. ISA Transactions 2016; 63, 401-412.

[10] Wen J, Yang H, Tong X, Li K, Wang S, \& Li Y. Optimization investigation on configuration parameters of serrated fin in plate-fin heat exchanger using genetic algorithm. International Journal of Thermal Sciences 2016; 101, 116-125.

[11] Canbulut F, Eğik Plakalı Eksenel Pistonlu Pompalarda Hidrostatik Hidrodinamik Prensipli Pabuçların Teorik ve Deneysel Analizi. Doktora Tezi, Erciyes Üniversitesi Fen Bilimleri Enstitüsü, Kayseri, 1990.

[12] Erdoğuş HB, Dairesel Cepli Hidrostatik Eksenel Kaymalı Yatakların Performansında Etkili Olan Parametrelerin Optimum Tasarımı. Yüksek Lisans Tezi, Erciyes Üniversitesi Fen Bilimleri Enstitüsü, Kayseri, 2008.

[13] Akkurt M. Makine Elemanları-İkinci Cilt. İstanbul: İTÜ, 1980; s: 141-170.

[14] Karaboğa D. Yapay Zeka Optimizasyon Algoritmaları. Ankara: Atlas Yayın-Dağıtım, Yayın No:38, 2004.

[15] Bhoskar MT, Kulkarni MOK, Kulkarnim MNK, Patekar MSL, Kakandikar GM \& Nandedkar VM. Genetic algorithm and its applications to mechanical engineering: A review. Materials Today: Proceedings 2015; 2(4-5), 2624-2630.

[16] Kaveh A, ve Ghazaan MI. Enhanced whale optimization algorithm for sizing optimization of skeletal structures. Mechanics Based design of structures and Machines 2017; 45(3), 345-362.

[17] Tosun E, Frezeleme İşlemlerinde Genetik Algoritma Yaklaşımı ile Kesme Koşullarının Optimizasyonu. Yüksek Lisans Tezi, Selçuk Üniversitesi Fen Bilimleri Enstitüsü, Konya, 2006.

[18] Düzgün S, Tornalamada İşem Parametrelerinin Optimizasyonunda Genetik Algoritma Çalışmaları ve Uygulaması. Yüksek Lisans Tezi, Marmara Üniversitesi Fen Bilimleri Enstitüsü, İstanbul, 2006. 